\title{
A homozygous mutation in the highly conserved Tyr60 of the mature IGF1 peptide broadens the spectrum of IGF1 deficiency
}

\author{
Ana Claudia Keselman ${ }^{1, *}$, Ayelen Martin ${ }^{1, *}$, Paula Alejandra Scaglia1, Nora María Sanguineti, \\ Romina Armando², Mariana Gutiérrez', Débora Braslavsky', María Gabriela Ballerini', \\ María Gabriela Ropelato', Laura Ramirez', Estefanía Landi', Sabina Domené1, Julia F Castro, \\ Hamilton Cassinelli', Bárbara Casali' ${ }^{1}$, Graciela del Rey1, Ángel Campos Barros ${ }^{3}$, Julián Nevado Blanco ${ }^{3}$, \\ Horacio Domené ${ }^{1}$, Héctor Jasper', Claudia Arberas², Rodolfo A Rey', Pablo Lapunzina-Badía ${ }^{3}$, Ignacio Bergadá1 \\ and Patricia A Pennisi ${ }^{1}$
}

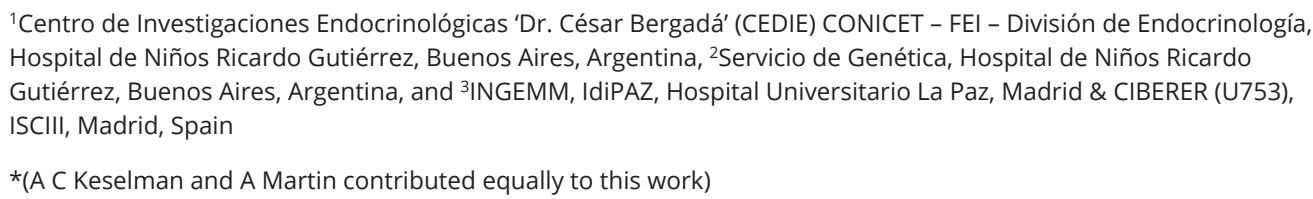

Correspondence should be addressed to P A Pennisi Email

ppennisi@cedie.org.ar

\begin{abstract}
Background: IGF1 is a key factor in fetal and postnatal growth. To date, only three homozygous IGF1 gene defects leading to complete or partial loss of IGF1 activity have been reported in three short patients born small for gestational age. We describe the fourth patient with severe short stature presenting a novel homozygous IGF1 gene mutation.

Results: We report a boy born from consanguineous parents at 40 weeks of gestational age with intrauterine growth restriction and severe postnatal growth failure. Physical examination revealed proportionate short stature, microcephaly, facial dysmorphism, bilateral sensorineural deafness and mild global developmental delay. Basal growth hormone (GH) fluctuated from 0.2 to $29 \mathrm{ng} / \mathrm{mL}$, while IGF1 levels ranged from -1.15 to 2.95 SDS. IGFBP3 was normal-high. SNP array delimited chromosomal regions of homozygosity, including 12q23.2 where IGF1 is located. IGF1 screening by HRM revealed a homozygous missense variant NM_000618.4(IGF1):c.322T>C, p.(Tyr108His). The change of the highly conserved Tyr60 in the mature IGF1 peptide was consistently predicted as pathogenic by multiple bioinformatic tools. Tyr60 has been described to be critical for IGF1 interaction with type 1 IGF receptor (IGF1R). In vitro, HEK293T cells showed a marked reduction of IGF1R phosphorylation after stimulation with serum from the patient as compared to sera from age-matched controls. Mutant IGF1 was also less efficient in inducing cell growth. Conclusion: The present report broadens the spectrum of clinical and biochemical presentation of homozygous IGF1 defects and underscores the variability these patients may present depending on the IGF/IGF1R pathway activity.
\end{abstract}

\section{Introduction}

The insulin-like growth factors (IGFs) comprise a family of peptides that play important roles in mammalian growth and development. IGF1, a 70-residue polypeptide,

mediates many of the growth promoting actions of growth hormone (GH) and has intrinsic growth, metabolic and mitogenic effects (1). IGF1 is essential for 
both fetal and postnatal growth and development (2). During fetal growth, however, these processes are largely $\mathrm{GH}$ independent $(3,4,5)$

Though the major source of circulating IGF1 is the liver, it is also locally produced in a wide variety of tissues having well-defined endocrine and paracrine/autocrine modes of action (6). IGF1 circulates mainly bound to IGF-binding proteins, (IGFBP) -3 or -5 and acid labile subunit (ALS), forming a large ternary complex that prolongs its halflife and modulates its bioactivity. This complex formation depends on GH secretion during postnatal life (7).

To date, human homozygous IGF1 gene defects have been reported in a very few cases $(8,9,10,11,12)$. The first case, reported by Woods et al., had a partial deletion of the IGF1 gene resulting in intrauterine growth failure, severe postnatal growth retardation, sensorineural deafness, and mental retardation associated with undetectable circulating IGF1 (8). The second case with a homozygous IGF1 alteration reported had a similar clinical phenotype but extremely high serum IGF1 levels (9). The third case had a homozygous missense IGF1 mutation resulting in a milder phenotype associated with variable serum IGF1 levels (10).

Here we describe a patient with a novel homozygous IGF1 mutation c.322T>C, p.Tyr108His, leading to severe pre- and post-natal growth failure, microcephaly, developmental delay and bilateral sensorineural deafness, associated with normal to mildly elevated circulating IGF1, underscoring the variability of the clinical and biochemical presentations of IGF1 gene defects.

\section{Patient and methods}

Clinical and auxological parameters: height and sitting height were determined using a wall mounted stadiometer, head circumference (HC) was assessed with a tape measure, and weight, using a calibrated scale. Height $(\mathrm{cm})$, weight $(\mathrm{kg})$ and sitting height/height ratio were expressed in standard deviation score (SDS) based on Argentinean references $(13,14)$. HC was expressed in $\mathrm{cm}$ and SDS using Dutch references (15). Body mass index SDS and height velocity SDS were calculated according to US references $(16,17)$. Parents were informed of the purpose of the study and written consent was obtained. The study was approved by the Ethics Committee of Hospital de Niños Dr. Ricardo Gutierrez, Buenos Aires, Argentina.

\section{Hormonal assays}

Samples were obtained from the proband, his parents and a half maternal brother. Plasma GH, IGF1 and IGFBP3 concentrations were measured by a chemiluminescent immunometric assay (IMMULITE® 2000system, Siemens Healthcare Diagnostics Products Ltd.), as previously reported (18). Intra- and inter-assay coefficients of variation were $<7.2 \%$ for all serum measurements. A second method was used for IGF1 measurements (Cobas e411 analyzer; Roche Diagnostics, 'ECLIA' IGF-I, Roche). IGF1 (ng/mL) and IGFBP3 $(\mu \mathrm{g} / \mathrm{mL})$ SDS were calculated based on Argentinean references (19). TSH, free T4 (FT4), cortisol, prolactin, LH, FSH, testosterone and insulin levels were determined by electrochemiluminescence (Cobas e411 analyzer; Roche Diagnostics GmbH), antithyroperoxidase antibodies by chemiluminescence assay (IMMULITE-2000 system; Siemens Healthcare Diagnostics Products Ltd.), anti-Müllerian hormone (AMH) by an enzyme-linked immunoassay (EIA AMH/MIS®, BeckmanCoulter Co., Marseilles, France).

\section{Genetic studies}

Genomic DNA from the patient and his parents and a maternal half-brother was extracted from peripheral venous blood by CTAB method (20), as previously described (21). Multiplex ligation-dependent probe amplification (MLPA) for subtelomeric regions was carried out using the Human Telomere-5 P070-B3 MLPA kit (MRC Holland, Amsterdam, The Netherlands) according to the manufacturer's instructions. Exon dosage was calculated using Coffalyser Net software (MRC Holland). Infinium CytoSNP-850K SNP array (Illumina) was used to perform aCGH-SNP in the proband's sample. IGF1 exons, intron/exon boundaries and known regulatory regions were PCR amplified and analyzed by high-resolution melting, as previously described (22). Fragments displaying abnormal melting pattern were sequenced with specific oligonucleotides in an ABI 3500 DNA analyzer. Oligonucleotide sequences are available upon request. Additionally, patient's and parents' samples were analyzed by targeted next-generation sequencing with a custom panel (EZ-Capture, Nimblegen, Roche) including a total of 433 genes implicated in the etiology of or associated with, syndromic and non-syndromic short stature (gene list available upon request). Peripheral blood karyotype was performed using high-resolution GTG banding.

\section{In silico molecular modeling}

Multiple sequence alignments among IGF1 from different species and among IGF1, IGF2 and Insulin were performed 
with PRALINE program (http://www.ibi.vu.nl/programs/ pralinewww/) using reference sequences obtained from Uniprot. Molecular model figures were prepared based on the crystal structure of the mature hIGF1 (PDB accession code 1GZR) (23) using the molecular graphics program PyMOL (PyMOL Molecular Graphics System, Version 1.8.4.0, Schrödinger, LLC, http://www.pymol.org/) which was also used to model in silico the Tyr108His mutation. Tyr108 is equivalent to Tyr60 in IGF1 mature peptide. We used the mature IGF1 peptide amino acid numbering for the molecular modeling in order to maintain the nomenclature of the original hIGF1 crystal structure publication. Side chain conformation of histidine was selected from the PyMOL backbone-dependent rotamer library considering minimal steric clashes with surrounding residues.

\section{IGF1 extraction by acid chromatography}

Serum was exposed to C18 Sep-Pak column (Waters Associates, Milford, MA, USA) for acid chromatography extraction to separate the IGFs from IGFBPs as previously described (24). To dissociate IGFs from IGFBPs, $100 \mu \mathrm{L}$ of each serum were incubated with $150 \mu \mathrm{L}$ of $0.5 \mathrm{~N} \mathrm{HCl}$ for $1 \mathrm{~h}$ at $37^{\circ} \mathrm{C}$. After incubation samples were seeded in SepPak columns that were prewet with $5 \mathrm{~mL}$ acetonitrile and then rinsed with $5 \mathrm{~mL}$ water. Samples entered the columns by gravity. Unbound proteins were eluted by rinsing the columns with $10 \mathrm{~mL} 4 \%$ acetic acid and IGFs were eluted with $1 \mathrm{~mL}$ of methanol. Solvents were removed from the sample using a SpeedVac vacuum concentrator. Once dried, pellets were resuspended in different volumes of DMEM culture medium to obtain equal concentrations of IGF1 for all samples.

\section{IGF1 receptor (IGF1R) phosphorylation}

HEK293 cells were grown in Dulbecco's modified Eagle's medium supplemented with $10 \%$ FBS at $37^{\circ} \mathrm{C}$ in a humidified 5\% $\mathrm{CO}_{2}$ environment. Cells were seeded on six-well plates, allowed to grow up to $70 \%$ confluence, and starved overnight with serum-free medium. Next morning, cells were incubated for $10 \mathrm{~min}$ with equivalent concentrations of extracted IGF1 and direct serum from the patient, his mother, father, brother and age and sexmatched control individuals. Cells stimulated with $20 \mathrm{nM}$ recombinant human (rh)-IGF1 were used as positive control for IGF1R phosphorylation. Cells cultured in serum-free medium without stimulation were used as basal condition. After stimulation, cells were harvested on lysis buffer containing protease inhibitors, and proteins were extracted as previously described (25). Experiments were performed in duplicates.

\section{Western blotting}

After extraction, protein concentration was determined using the Bradford reagent. Fifty micrograms of proteins were resolved by SDS-PAGE and transferred to PVDF membranes. Blots were blocked and probed with antibodies recognizing the phosphorylated fraction or total IGF1R protein (Cell Signaling Technology).

\section{Proliferation assay}

HEK293 cells $(4 \times 104)$ were seeded on 24-well plates in complete medium (CM) (DMEM, 10\% fetal bovine serum (FBS)). Twenty-four hours after seeding, cells were harvested by trypsinization and counted after 0.5\% trypan blue staining to determine the initial number of cells (Time 0). In the remaining plates, medium was replaced by low serum medium (LSM) (DMEM, 1\% FBS) or medium supplemented with serum samples from the patient, relatives or controls containing equivalent amount of IGF1. After $48 \mathrm{~h}$ of culture, cells were trypsinized and counted using 0.5\% trypan blue staining. Each condition was performed in triplicates.

\section{Results}

\section{Patient}

The index case was referred to the Endocrine Division of the Hospital de Niños Dr. Ricardo Gutierrez, Buenos Aires, at 3.2 years of age because of short stature. He was born from consanguineous parents at 40 weeks of gestational age (GA), with intrauterine growth retardation (IUGR): birth weight and length were $1910 \mathrm{~g}$ $(-3.1$ SDS $)$ and $38 \mathrm{~cm}$ ( -6.3 SDS), respectively. At 3.2 years, height was $74 \mathrm{~cm}$ ( -6.2 SDS), sitting height/height ratio 0.567 (-0.4 SDS), weight $6.1 \mathrm{~kg}(-5.1 \mathrm{SDS})$ and HC $41 \mathrm{~cm}$ (-6.1 SDS). Physical examination revealed facial dysmorphism including frontal bossing, triangular face, bulbous nose, full lips, and retrognathia (Fig. 1). He also presented bilateral sensorineural deafness, mild language and motor delay and hyperactive behavior. His school performance was poor, revealing learning difficulties. His last clinical evaluation at 7.8 years showed persisting postnatal growth failure: height, $90.2 \mathrm{~cm}$ (-6.5 SDS); weight, $9.6 \mathrm{~kg}$ (-5.0 SDS); HC, $44.2 \mathrm{~cm}$ (-4.9 SDS) with 
A

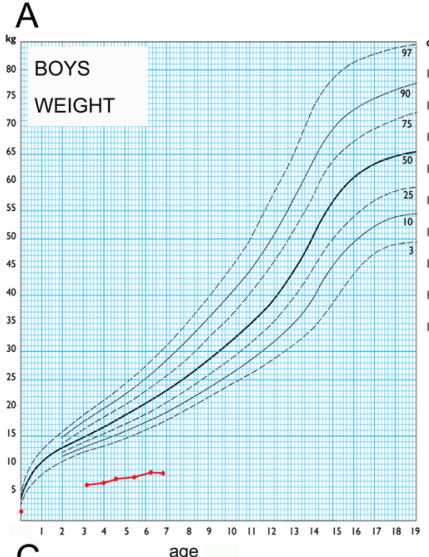

B

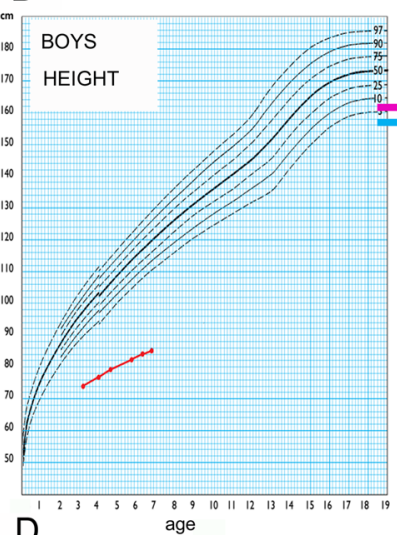

BOYS

60. HEAD

CIRCUMFERENCE
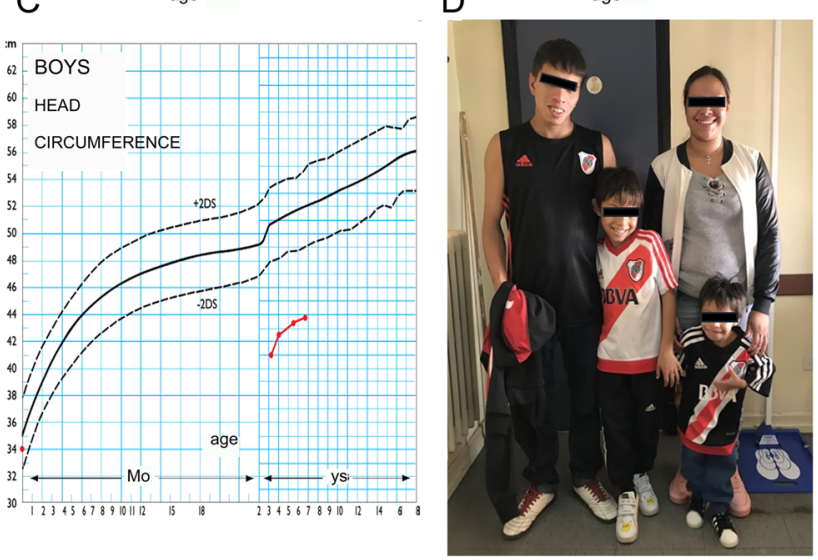

E

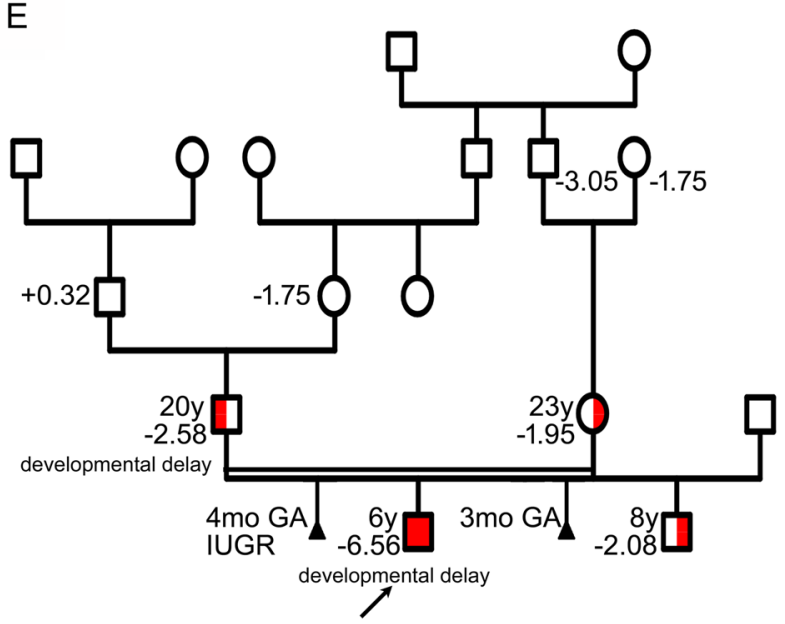

Figure 1

Growth curves, patient and pedigree. Weight (A), height (B), and head circumference (C) curves between the ages of 3 and 7 years. (D) Patient at the age of 7 years. Parents gave their informed consent for the publication of pictures. (E) Pedigree. Patient's parents and half-brother were heterozygous for IGFI mutation. Heights are indicated as the number of SDS values relative to the mean, based on Argentinean reference values. A full colour version of this figure is available at https://doi. org/10.1530/EJE-19-0563. slow growth height velocity (Table 1 ). Routine blood tests (RBC, WBC, glucose, BUN, creatinine, SGOT, SGPT, cholesterol, triglycerides, celiac antibodies) showed normal results. TSH, FT4, cortisol, prolactin, insulin, gonadotropins, testosterone and AMH levels were within normal ranges. Basal levels of GH and IGF1 were variable (Table 2). IGF1 measurements were confirmed using a second method (data not shown). Our results are in accordance to high intra-subject variability for IGF1 observed by other authors (26). Normal-to-high IGFBP3 values were found as shown in Table 2 . His karyotype was normal $(46, \mathrm{XY})$.

Parental height and HC were $148.8 \mathrm{~cm}(-2.0$ SDS) and $52.2 \mathrm{~cm}(-1.8$ SDS) for his mother, and $155.2 \mathrm{~cm}(-2.6$ SDS) and $52.0 \mathrm{~cm}(-3.1 \mathrm{SDS})$ for his father. Mid-parental height was 158.2 ( -2.14 SDS). Mother's and father's birth weights were 2500 and $1900 \mathrm{~g}$, respectively. His maternal half-brother's height and HC were $118.0 \mathrm{~cm}(-2.0 \mathrm{SDS})$ and $49.6 \mathrm{~cm}(-1.8 \mathrm{SDS})$ at 8 years of age. He was born at 39 weeks of GA with weight $3000 \mathrm{~g}$ ( -0.7 SDS) and length $44 \mathrm{~cm}$ ( -3.1 SDS). The mother had had two spontaneous miscarriages the first at 4 months of GA, with IUGR, the second at 3 months of GA. Table 3 shows available auxological and biochemical data for family members.

\section{Identification of a new missense variant in the A domain of IGF1}

SNP array showed multiple chromosomal regions of homozygosity, including 12q23.2 where IGF1 is located, a potential candidate gene for the patient's phenotype. IGF1 coding and known regulatory regions were analyzed by highresolution melting. Fragments displaying abnormal melting pattern were sequenced. The patient was homozygous and his parents and half-brother heterozygous for a novel IGF1 missense variant NM_000618.4(IGF1):c.322T>C, p.(Tyr108His). This variant changes a highly conserved Tyr residue, located in the A domain of IGF1 and has been described to be critical for its interaction with IGF1R (27). The presence of further variants in IGF1R, IGF2, IGF2R, IGFBP3, or IGFALS was excluded by targeted NGS analysis (average coverage: $385.9 \times, 370.12 \times, 364.3 \times, 297.3 \times$ and $296.5 \times$, respectively).

\section{In silico analysis}

In silico studies consistently predicted the NM_000618.4(IGF1):c.322T>C, p.(Tyr108His) variant as pathogenic using multiple bioinformatics tools (CADD, DANN, GERP, FATHMM, LRT, MutationAssessor, 
Table 1 Auxological parameters.

\begin{tabular}{l}
$\mathbf{C A}$ \\
\hline$y$ \\
\hline $3^{2 / 12}$ \\
$4^{0 / 12}$ \\
$5^{6 / 12}$ \\
$6^{10 / 12}$ \\
$7^{9 / 12}$
\end{tabular}

\begin{tabular}{|c|c|}
\hline \multicolumn{2}{|c|}{ Weight } \\
\hline $\mathrm{Kg}$ & SDS $^{*}$ \\
\hline 6.1 & -5.1 \\
\hline 6.7 & -4.9 \\
\hline 7.9 & -5.6 \\
\hline 8.2 & -5.2 \\
\hline 9.7 & -5.0 \\
\hline
\end{tabular}

\begin{tabular}{|c|c|}
\hline \multicolumn{2}{|c|}{ Height } \\
\hline $\mathrm{Cm}$ & SDS $^{*}$ \\
\hline 74 & -6.2 \\
\hline 76.5 & -6.4 \\
\hline 82 & -6.5 \\
\hline 85.8 & -6.7 \\
\hline 90.2 & -6.5 \\
\hline
\end{tabular}

\begin{tabular}{|c|c|}
\hline \multicolumn{2}{|c|}{ BMI } \\
\hline $\mathrm{kg} / \mathrm{m}^{2}$ & $\mathrm{SDS}^{\dagger}$ \\
\hline 11.1 & -6.7 \\
\hline 11.5 & -5.6 \\
\hline 11.7 & -5.3 \\
\hline 11.3 & -6.2 \\
\hline 11.9 & -4.5 \\
\hline
\end{tabular}

\begin{tabular}{ccc}
\hline \multicolumn{2}{c}{ SH/H ratio } \\
${$\cline { 1 - 1 } \cline { 1 - 1 }$} }$ & & SDS \\
\cline { 1 - 1 }-567 & & -0.4 \\
- & & - \\
- & & - \\
0.536 & & 0.0
\end{tabular}

\begin{tabular}{|c|c|}
\hline \multicolumn{2}{|c|}{ HC } \\
\hline $\mathrm{Cm}$ & $\mathrm{SDS}^{\S}$ \\
\hline 41 & -5.6 \\
\hline 42.5 & -5.1 \\
\hline 43.4 & -4.8 \\
\hline 43.8 & -4.8 \\
\hline 44.2 & -4.9 \\
\hline
\end{tabular}

\begin{tabular}{|c|c|c|}
\hline \multicolumn{2}{|c|}{ HV } & BA \\
\hline $\mathrm{cm} / \mathrm{y}$ & SDS\| & $y$ \\
\hline - & - & \\
\hline 3.9 & NA & \\
\hline 3.4 & -4.0 & \\
\hline 2.5 & -5.4 & 4 \\
\hline 4.4 & -1.9 & 4 \\
\hline
\end{tabular}

*SDS were calculated relative to the mean, based on Argentinean reference values (13). ${ }^{\dagger}$ SDS were calculated based on data from CDC (16). ${ }^{\ddagger}$ SDS were calculated using Argentinean references (14). ${ }^{\text {SSDS }}$ were calculated based on Dutch references (15). USDS were calculated using U.S. references (17). $\mathrm{BA}$, bone age; BMI, body mass index; $\mathrm{CA}$, chronological age; $\mathrm{HC}$, head circumference; HV, height velocity; NA, not available; SH/H ratio, sitting height/ height ratio.

MutationTaster, PROVEAN, FATHMM-MKL and SIFT) vs no benign predictions. The analysis of positional conservation of Tyr108 residue by multiple sequence alignment from ten species showed that Tyr108 is highly conserved among species. Tyr108 is also conserved among IGF2 and insulin proteins (Fig. 2A). The mature structure of hIGF1, reached after processing all transcript IGF1 isoforms, consists mainly of three-helix bundle and a flexible loop (C-region), which extends away from the core of IGF1 (23). The Tyr108 is equivalent to Tyr60 in this mature structure. Tyr60 is a key residue involved in IGF1R binding (27) and is located neighboring the C-neck region and completely buried under the side chains of Arg56, Lys27, and Met59 (Fig. 2B). Despite its position toward the core of the molecule, the hydroxyl group of Tyr60 forms a hydrogen bond with Glu46. When Tyr60 is changed into a smaller histidine, no hydrogen bond is formed between the residue and Glu46 (Fig. 2C). However, residues involved in the interaction with IGFBP3 (28) should not be affected according to the molecular model (Fig. 2D).

\section{Impaired ability to induce IGF1R phosphorylation}

The effect of the p.(Tyr108His) mutation on the ability to activate IGF1R was tested using HEK293 cells.
A short stimulus with serum samples before and after acid chromatography to separate IGF1 from IGFBPs, was performed. As shown in Fig. 3A, stimulation with $20 \mathrm{nM}$ of rhIGF1 provoked a strong activation of IGF1R. Similar effects were obtained after 10 min of stimulation using direct or extracted samples from controls (Fig. 3A, lines 3 and 9). However, a much weaker stimulation was observed when patient's serum or extracted samples were used. This result suggests an impaired IGF1R activation by mutant IGF1 (Fig. 3A, lines 5 and 11). When samples from heterozygous relatives were tested, the responses were lower than control's but stronger than the proband's.

\section{Impaired ability to stimulate cell proliferation}

To assess the ability of p.Tyr108His-IGF1 to stimulate proliferation in HEK293T cells, cells were cultured for $48 \mathrm{~h}$ with medium supplemented with serum from the patient and his first-degree relatives and age and sex-matched controls (Fig. 3B and C). While controls were able to duplicate the cell number after $48 \mathrm{~h}$ of culture, serum from the patient did not increase the cell count. As in the phosphorylation studies, samples from heterozygous subjects had intermediate proliferation effects.

Table 2 Hormonal measurements.

\begin{tabular}{|c|c|c|c|c|c|c|c|}
\hline & \multicolumn{6}{|c|}{ CA $(y)$} & \multirow[b]{2}{*}{$\mathbf{R R}$} \\
\hline & $3^{4 / 12}$ & $3^{7 / 12}$ & $4^{0 / 12}$ & $5^{9 / 12}$ & $6^{5 / 12}$ & $6^{10 / 12}$ & \\
\hline $\mathrm{GH}, \mathrm{ng} / \mathrm{mL}$ & 9 & 29.10 & 1.57 & 2.97 & 0.20 & 0.48 & 1-8 years: $0.1-5$ \\
\hline IGF1, ng/mL & 89 & 108 & 47 & 75 & 206 & 164 & $1-5$ years: $29-118$ \\
\hline SDS & +0.31 & +0.75 & -1.15 & -0.71 & +2.95 & +2.12 & 5-7 years: 39-118 \\
\hline IGFBP3, $\mu \mathrm{g} / \mathrm{mL}$ & 3.86 & 4.12 & 2.66 & 2.3 & 5.3 & 4.5 & $1-5$ years: $1.7-4.2$ \\
\hline SDS & +1.22 & +1.55 & -0.32 & -1.58 & +2.31 & +1.27 & 5-8 years: $2-4.4$ \\
\hline \multirow[t]{2}{*}{ Insulin, $\mu U / m L$} & & & 2.6 & & 5.4 & 1.7 & $1-5$ years: $1.5-6.5$ \\
\hline & & & & & & & 5-13 years: $1.8-12$ \\
\hline
\end{tabular}


Table 3 Clinical and biochemical features in family members.

\begin{tabular}{|c|c|c|c|c|c|c|c|c|c|c|c|c|c|}
\hline \multirow[b]{2}{*}{ Family member } & \multirow{2}{*}{$\frac{\mathbf{C A}}{\mathrm{y}}$} & \multicolumn{2}{|c|}{ Height } & \multicolumn{2}{|c|}{ BMI } & \multicolumn{2}{|c|}{ SH/H ratio } & \multicolumn{2}{|c|}{ HC } & \multicolumn{2}{|c|}{ IGF1 } & \multicolumn{2}{|c|}{ IGFBP3 } \\
\hline & & $\mathrm{cm}$ & SDS $^{*}$ & $\mathrm{~kg} / \mathrm{m}^{2}$ & $\mathrm{SDS}^{\dagger}$ & Ratio & SDS $^{\ddagger}$ & $\mathrm{cm}$ & SDS $^{\S}$ & $\mathrm{ng} / \mathrm{mL}$ & RR & $\mu \mathrm{g} / \mathrm{mL}$ & RR \\
\hline Mother & 23 & 148.8 & -2.0 & 28.3 & 1.3 & 0.530 & -0.2 & 52.2 & -1.8 & 182 & $107-367$ & 4 & $3.4-7.8$ \\
\hline Father & 20 & 155.2 & -2.6 & 22.4 & -0.2 & 0.522 & -0.1 & 52 & -3.1 & 163 & $105-346$ & 5 & $2.9-7.2$ \\
\hline Half-brother & 8.7 & 118 & -2.1 & 15.5 & -0.2 & 0.525 & -1.0 & 49.6 & -1.8 & 155 & 39-132 & 4.4 & $2.2-5.6$ \\
\hline
\end{tabular}

*SDS were calculated based on Argentinean reference values (13). `SDS were calculated based on data from CDC (16). ${ }^{\ddagger}$ SDS were calculated using Argentinean references (14). §SDS were calculated based on Dutch references (15).

$\mathrm{RR}$, reference range.

\section{Discussion}

We describe a patient with severe short stature born from consanguineous parents with a novel homozygous substitution of a highly conserved tyrosine residue in the A domain of IGF1. This is, to our knowledge, the sixth IGF1 variant reported in the literature $(8,9,10$, $11,12)$, and the third associated with marked pre- and postnatal growth restriction, microcephaly, micro/ retrognathia, sensorineural deafness and intellectual deficit $(8,9)$. In addition to the three previous well documented cases of patients with IGF1 defects that were supported by functional analysis $(8,9,10)$, two other IGF1 variants have been reported: one (11) was later shown to be a non-pathogenic variant (29). In the other (12), a homozygous IGF1 mutation is reported in two members of a Saudi Arabian family, of whom some clinical (Table 4) but no functional or in silico data are available. A substitution of Arginine by Tryptophan is reported in a position of the mature IGF1 peptide that is not highly conserved. Using ACMG guidelines, we found that this mutation is classified as a variant of uncertain significance (VUS).

The missense variant presented in this report resulted in a substitution for histidine of a highly conserved tyrosine residue, located in a region of the A domain of IGF1 that has been reported to be critical for its interaction with IGF1R (27). Previous cases with such a severe phenotype presented undetectable (8) or, on the opposite, very high (9) IGF1 levels in circulation. Conversely, our patient had normal to mildly elevated serum IGF1, underscoring the importance of considering the heterogeneity of the presentation of IGF1 deficiency to avoid misled diagnoses in patients with short stature.

The change of the highly conserved Tyr108 residue (Tyr60 in the mature IGF1 peptide) was consistently predicted as pathogenic by multiple bioinformatic tools. In silico analysis predicts that this substitution may lead to conformational changes in the receptor binding domain that in turn could destabilize the contact of IGF1 with its receptor (27). Evidence of a decreased ability to activate the IGF1R was obtained in vitro using serum from our patient, which proved that phosphorylation of the IGF1R was diminished as compared to age-matched controls. Furthermore, Tyr108His-IGF1 also induced cell growth less efficiently than IGF1 from controls. Early work in the 1990s searching for determinants on human IGF1 for its receptors and binding proteins had identified the Tyr60 of the mature IGF1 (i.e. Tyr108 replaced by a histidine in our patient) as a conserved residue with paramount relevance in the maintenance of binding to its receptor (27). Other reports showed that substitution of valine by methionine in position 92 (Met 44 in the mature protein), also in the A domain (9), substantially impaired IGF1R binding by a factor of 90. On the other hand, residues involved in the interaction with IGFBP3 $(27,28,30)$ should not be affected according to the molecular model. Recombinant IGF1 peptides with modifications such as p.Arg84Gln and p.Val92Met have normal binding to IGFBP3 $(9,10)$. Accordingly, in our study, in vitro experiments showed that when IGFBPs were removed from the patient's serum by acid chromatography, the phosphorylated band of IGF1R was stronger than in the presence of IGFBPs, suggesting that in unextracted serum, IGF1 was mainly bound to its binding proteins. Taken together, our results show that the substitution of tyrosine 108 by histidine in the mature IGF1 peptide renders the molecule highly likely to have a reduced affinity for IGF1R.

Several authors $(31,32,33)$ have reported short stature and/or microcephaly in patients carrying heterozygous IGF1 mutations. Walenkamp et al (9) also described the impact of p.Val92Met-IGF1 on a wide pedigree of heterozygous carriers. In the present case, auxological data of the parents and half-brother could suggest that heterozygosity for the mutation leads to mild to moderate short stature and microcephaly. Unfortunately, we did not have the possibility to study any other member of this family to further support this observation. 
A

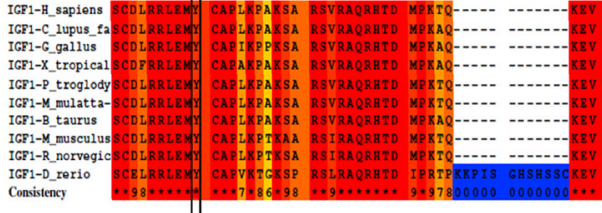

B

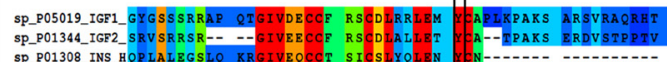
sp_P01308_INS_BQP LALEGS Consistency
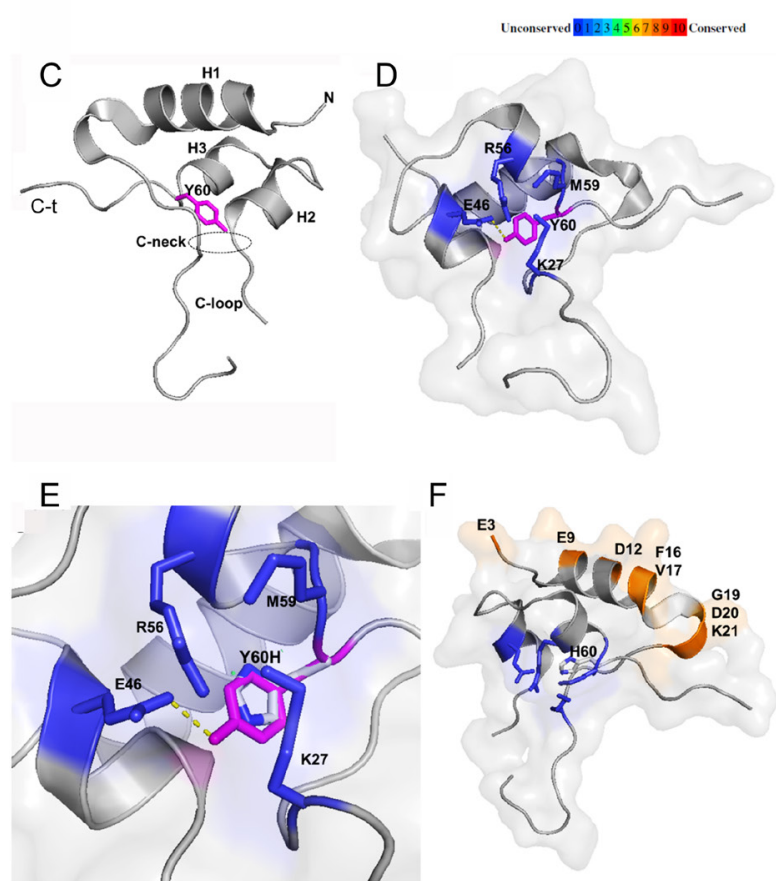

F

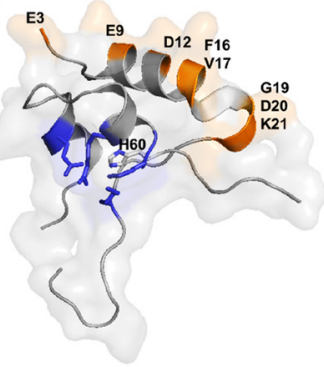

Figure 2

Multiple sequence alignments among different species (A) and among IGF2 and insulin proteins (B) were done with PRALINE software. The color scheme indicates the least conserved alignment position (dark blue), to the most conserved alignment position (red). (C, D, E and F) Cartoon representations of the mature hIGF1 structure (PDB 1GZR). (C) Main structure of IGF1 consisting of three helices ( $\mathrm{H} 1, \mathrm{H} 2$ and $\mathrm{H} 3$ ) and a C-loop. Tyr60 (stick, magenta) is located close to the C-neck (dotted lines); $\mathrm{N}$ and $\mathrm{C}$-t are the $\mathrm{N}$ - and C-termini. (D) The structure has been rotated to show residues Arg56, Lys27, and Met59 (sticks, blue) protecting Tyr60. The only exposed portion of Tyr60 is the hydroxyl group that forms a hydrogen bond (dotted yellow lines) with Glu46. (E) The image has been expanded in Tyr60 area. Substitution of Tyr60 by His cause the loss of the hydrogen bond with Glu46. (F) Key residues involved in IGFBP3 interaction (Glu3, Glu9, Asp12, Phe16, Val17, Gly19, Asp20, Arg21, and Glu58) are shown in orange in cartoon representation. They are located on the surface of IGF1 far from the change Tyr60His. A full colour version of this figure is available at https://doi.org/10.1530/EJE-19-0563.
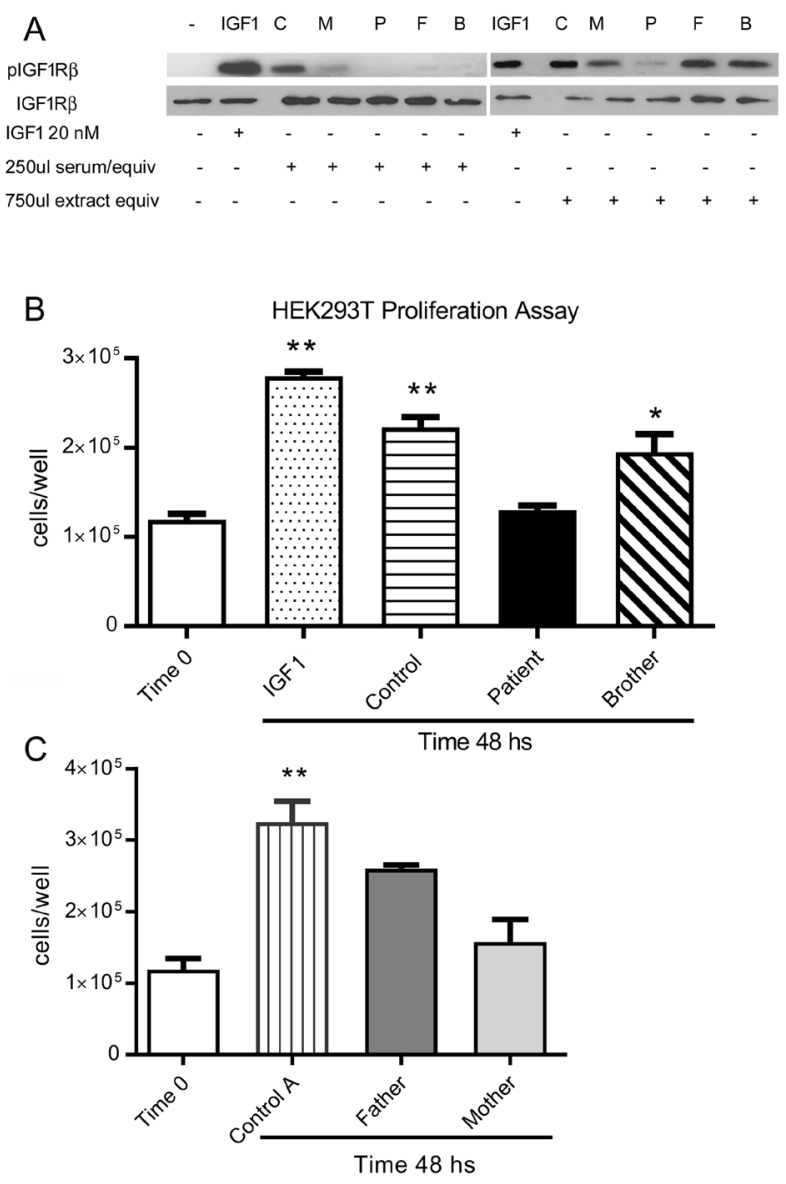

\section{Figure 3}

Activation of IGF1R and induction of cell growth by mutant Tyr108His-IGF1. (A) HEK293T cells are stimulated for 10 min with rhIGF1 or serum from the patient, his relatives and controls before and after IGFBPs extraction. Whole lysates ( $50 \mu \mathrm{g})$ were used for Western blotting, and membranes probed for phospho and total IGF1R. The result shown represents a typical experiment. Samples from the patient activate IGF1R less than samples from control and heterozygous individuals when applied directly on cultured cells as well as using extracts after acid chromatography for IGFBPs removal. (B and C) Cell count after 48-h culture with samples from the patient, controls and relatives. There was no increase in the number of cells at the end of the experiment when cultured with serum form the patient. Number of cells increased after rhIGF1 stimulation, as well as after incubation with serum from age-matched controls and heterozygous brother, one-way ANOVA, followed by Dunnett's multiple comparison test, $* * P<0.01$ vs time $0 ; * P<0.05$ vs time 0 (B). Samples from the father and the mother failed to increase the number of cells after $48 \mathrm{~h}$ incubation, compared to serum from age-matched controls; one-way ANOVA, followed by Dunnett's multiple comparison test, $* * P<0.01$ vs time 0 (C). $B$, brother; F, father; $M$, mother; $P$, proband. 


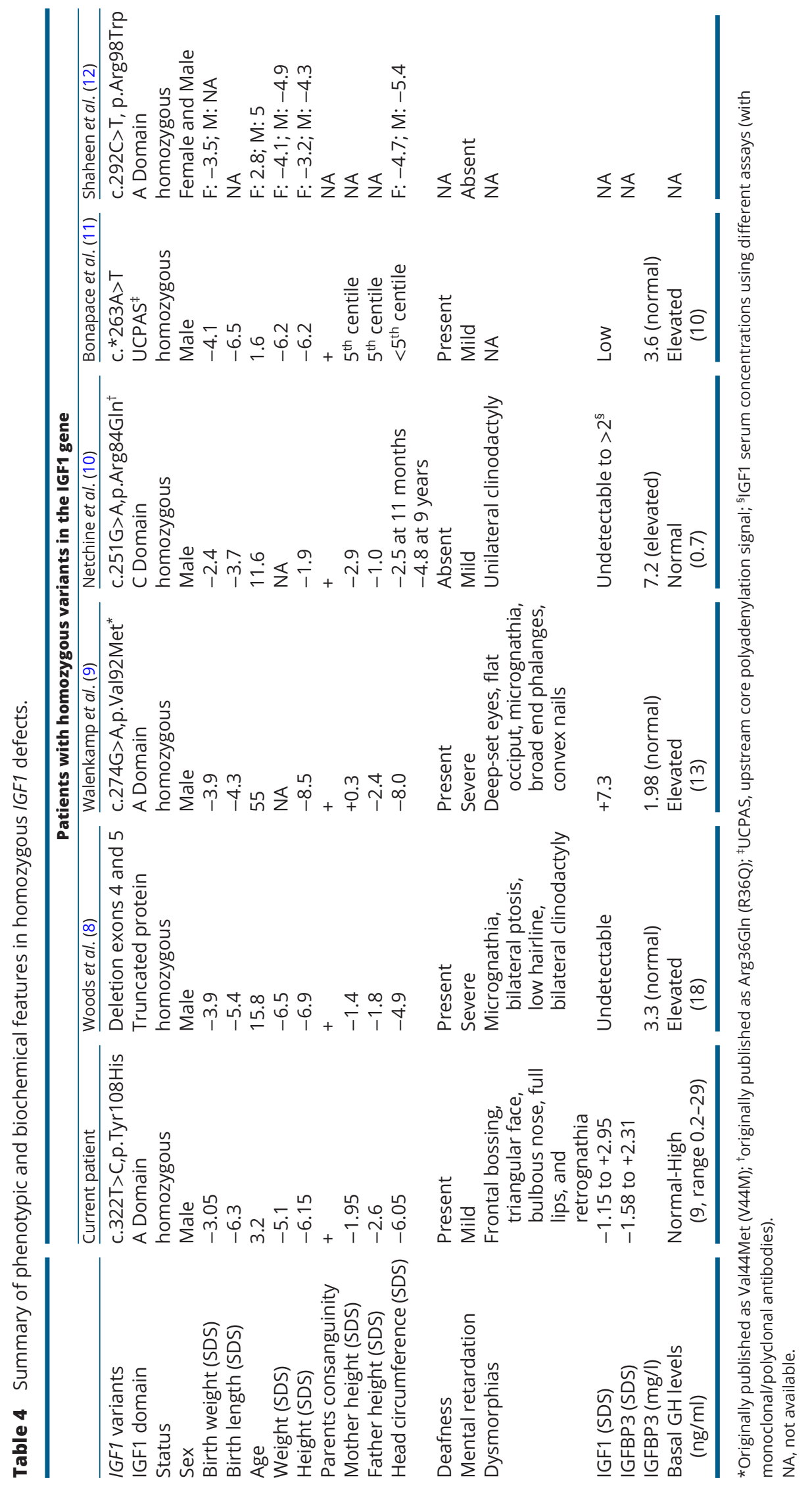


The first patient with severe IGF1 deficiency was reported in 1996 by Woods et al (8), describing a male born from consanguineous parents with a homozygous deletion of exon 4 and 5 of IGF1 gene resulting a severely truncated IGF1 protein (Table 4). GH levels were elevated, and serum IGF1 was undetectable at baseline and after a 4-day IGF1 generation test with normal levels of IGFBP3 and ALS. Clinical presentation but not biochemical features were very similar to the patient described here. In 2005, Walenkamp et al (9) described a 55-year-old male with a severe IGF1 deficiency phenotype, with final height of $118 \mathrm{~cm}$ (Table 4). Molecular analysis revealed a homozygous missense mutation in IGF1 gene predicting the change of valine 92 into methionine. Interestingly, IGF1 levels were at+7.3 SDS, and functional studies showed an about 90-fold decreased affinity of IGF1 for its receptor, which could explain the high levels of IGF1. Our patient had clinical features that could relate to a very low activity of IGF1, such as marked pre and postnatal growth retardation, microcephaly, sensorineural deafness and mental retardation. However, his IGF1 levels were normal or just above normal range. Therefore, patients with IGF1 molecular defects and a very severe clinical presentation, could have substantially different IGF1, IGFBP3, ALS and GH serum profiles. Thus, serum IGF1 could be elusive in the diagnosis of a child with IUGR, sensorineural deafness and severe postnatal growth failure.

The third patient, reported by Netchine et al. (10), was a boy with pre- and postnatal growth failure, but he had normal hearing and only a mild developmental delay (Table 4). IGF1 levels were variable between undetectable to +2 SDS measured by different assays. IGFBP3 and ALS, in the upper normal range. IGF1 gene showed a homozygous missense mutation that predicted the change of a highly conserved arginine located in $\mathrm{C}$ domain of the protein into a glutamine. The affinity of IGF1 for IGF1R was decreased by approximately four-fold, leading to diminished IGF1R phosphorylation. The patient reported in our study showed a more severe phenotype, but with a very similar GH/IGF1 axis serum profile. Therefore, our results suggest that similar serum profiles for $\mathrm{GH} / \mathrm{IGF}$ axis could be associated with variable clinical features. Furthermore, molecular defects in IGF1R have been reported in patients with similar clinical features, including IUGR and postnatal growth failure, despite variable GH-IGFs axis profiles. Heterozygous mutations in the IGF1R gene lead to incomplete resistance to IGF1, IUGR and postnatal growth failure, microcephaly, modest impairment of mental development and normal hearing, associated with normal or increased levels of IGF1 and IGFBP3 $(34,35)$.

In summary, many clinical and biochemical features may overlap within molecular defects in different genes belonging to the same signaling path. The report of our patient expands the spectrum of presentation of IGF1 defects and shows the variability these patients may present depending on the IGF/IGF1R pathway activity.

\section{Declaration of interest}

I certify that neither I nor my co-authors have a conflict of interest that is relevant to the matter or materials included in this work.

\section{Funding}

This work was supported by Consejo Nacional de Investigaciones Científicas y Técnicas, República Argentina, Grant PUE CEDIE \# 131. 2017; Instituto Nacional del Cáncer, Ministerio de Salud de la Nación, República Argentina, Grant 2015 (P A P); FIS 12/00649 from ISCIII, Spain and EU FEDER Funding (to A C B) and ENDOSCREEN S2010/BMD-2396, from Comunidad de Madrid, Spain \& EU FEDER FUNDING (to P L-B, J N B, and A C B).

\section{Acknowledgements}

The authors wish to thank Dr Saul Malozowski for his helpful discussion and revision of the manuscript. They also would like to thank Dr Mariana Del Pino for providing references and calculating SDS for SH/H ratio. Ignacio Bergadá and Patricia A Pennisi: Joint senior authors.

\section{References}

1 Lund PK. Insulin-like growth factor I: molecular biology and relevance to tissue-specific expression and action. Recent Progress in Hormone Research 199449 125-148. (https://doi.org/10.1016/B978-012-571149-4.50010-6)

2 Netchine I, Azzi S, Le Bouc Y \& Savage MO. IGF1 molecular anomalies demonstrate its critical role in fetal, postnatal growth and brain development. Best Practice and Research. Clinical Endocrinology and Metabolism 201125 181-190. (https://doi.org/10.1016/j. beem.2010.08.005)

3 Agrogiannis GD, Sifakis S, Patsouris ES \& Konstantinidou AE. Insulinlike growth factors in embryonic and fetal growth and skeletal development (Review). Molecular Medicine Reports 201410 579-584. (https://doi.org/10.3892/mmr.2014.2258)

4 Hellström A, Ley D, Hansen-Pupp I, Hallberg B, Löfqvist C, van Marter L, van Weissenbruch M, Ramenghi LA, Beardsall K, Dunger D et al. Insulin-like growth factor 1 has multisystem effects on foetal and preterm infant development. Acta Paediatrica 2016105 576-586. (https://doi.org/10.1111/apa.13350)

5 Ranke MB \& Wit JM. Growth hormone - past, present and future. Nature Reviews Endocrinology 201814 285-300. (https://doi. org/10.1038/nrendo.2018.22)

6 Livingstone C. Insulin-like growth factor-I (IGF-I) and clinical nutrition. Clinical Science 2013125 265-280. (https://doi. org/10.1042/CS20120663)

7 Rosenfeld RG \& Hwa V. The growth hormone cascade and its role in mammalian growth. Hormone Research 200971 36-40. (https://doi. org/10.1159/000192434) 
8 Woods KA, Camacho-Hübner C, Savage MO \& Clark AJL. Intrauterine growth retardation and postnatal growth failure associated with deletion of the insulin-like growth factor I gene. New England Journal of Medicine 1996335 1363-1367. (https://doi.org/10.1056/ NEJM199610313351805)

9 Walenkamp MJE, Karperien M, Pereira AM, Hilhorst-Hofstee Y, van Doorn J, Chen JW, Mohan S, Denley A, Forbes B, van Duyvenvoorde HA et al. Homozygous and heterozygous expression of a novel insulin-like growth factor-I mutation. Journal of Clinical Endocrinology and Metabolism 200590 2855-2864. (https://doi. org/10.1210/jc.2004-1254)

10 Netchine I, Azzi S, Houang M, Seurin D, Perin L, Ricort JM, Daubas C, Legay C, Mester J, Herich R et al. Partial primary deficiency of insulin-like growth factor (IGF)-I activity associated with IGF1 mutation demonstrates its critical role in growth and brain development. Journal of Clinical Endocrinology and Metabolism 2009 94 3913-3921. (https://doi.org/10.1210/jc.2009-0452)

11 Bonapace G, Concolino D, Formicola S \& Strisciuglio P. A novel mutation in a patient with insulin-like growth factor 1 (IGF1) deficiency. Journal of Medical Genetics 200340 913-917. (https://doi. org/10.1136/jmg.40.12.913)

12 Shaheen R, Faqeih E, Ansari S, Abdel-Salam G, Al-Hassnan ZN, Al-Shidi T, Alomar R, Sogaty S \& Alkuraya FS. Genomic analysis of primordial dwarfism reveals novel disease genes. Genome Research 201424 291-299. (https://doi.org/10.1101/gr.160572.113)

13 Lejarraga H, del Pino M, Fano V, Caino S \& Cole TJ. [Growth references for weight and height for Argentinian girls and boys from birth to maturity: incorporation of data from the World Health Organisation from birth to 2 years and calculation of new percentiles and LMS values]. Archivos Argentinos de Pediatria 2009107 126-133. (https://doi.org/10.1590/S0325-00752009000200006)

14 del Pino M, Orden AB, María A \& Arenas VF. Referencias argentinas para la evaluación de proporciones corporales desde el nacimiento hasta los 17 años Argentine references for the assessment of body proportions from birth to 17 years of age. Archivos Argentinos de Pediatria 2017115 234-240. (https://doi.org/10.5546/aap.2017.234)

15 Fredriks AM, van Buuren S, Burgmeijer RJ, Meulmeester JF, Beuker RJ, Brugman E, Roede MJ, Verloove-Vanhorick SP \& Wit JM. Continuing positive secular growth change in the Netherlands 1955-1997. Pediatric Research 200047 316-323. (https://doi. org/10.1203/00006450-200003000-00006)

16 Kuczmarski RJ, Ogden CL, Guo SS, Grummer-Strawn LM, Flegal KM, Mei Z, Wei R, Curtin LR, Roche AF \& Johnson C. CDC growth charts for the United States: methods and development. National Center for Health Statistics. In Vital and Health Statistics. Series 11 (246) 2002.

17 Kelly A, Winer KK, Kalkwarf H, Oberfield SE, Lappe J, Gilsanz V \& Zemel BS. Age-based reference ranges for annual height velocity in US children. Journal of Clinical Endocrinology and Metabolism 201499 2104-2112. (https://doi.org/10.1210/jc.2013-4455)

18 Ballerini MG, Braslavsky D, Scaglia PA, Keselman A, Rodríguez ME, Martínez A, Freire AV, Domené HM, Jasper HG, Bergadá I et al. Circulating IGF-I, IGFBP-3 and the IGF-I/IGFBP-3 molar ratio concentration and height outcome in prepubertal short children on rhGH treatment over two years of therapy. Hormone Research in Paediatrics 201788 354-363. (https://doi.org/10.1159/000479691)

19 Ballerini MG, Domené HM, Scaglia P, Martínez A, Keselman A, Jasper HG \& Ropelato MG. Association of serum components of the GH-IGFs-IGFBPs system with GHR-exon 3 polymorphism in normal and idiopathic short stature children. Growth Hormone and IGF Research 201323 229-236. (https://doi.org/10.1016/j. ghir.2013.08.003)

20 Del Sal G, Manfioletti G \& Schneider C. The CTAB-DNA precipitation method: a common mini-scale preparation of template DNA from phagemids, phages or plasmids suitable for sequencing. BioTechniques $19897514-520$.
21 Scaglia PA, Keselman AC, Braslavsky D, Martucci LC, Karabatas LM, Domené S, Gutiérrez ML, Ballerini MG, Ropelato MG, SpinolaCastro A et al. Characterization of four Latin American families confirms previous findings and reveals novel features of acid-labile subunit deficiency. Clinical Endocrinology 201787 300-311. (https:// doi.org/10.1111/cen.13361)

22 Arias-Salgado EG, Galvez E, Planas-Cerezales L, Pintado-Berninches L, Vallespin E, Martinez P, Carrillo J, Iarriccio L, Ruiz-Llobet A, Catalá A et al. Genetic analyses of aplastic anemia and idiopathic pulmonary fibrosis patients with short telomeres, possible implication of DNArepair genes. Orphanet Journal of Rare Diseases 201914 82. (https:// doi.org/10.1186/s13023-019-1046-0)

23 Brzozowski AM, Dodson EJ, Dodson GG, Murshudov GN, Verma C, Turkenburg JP, De Bree FM \& Dauter Z. Structural origins of the functional divergence of human insulin-like growth factor-I and insulin. Biochemistry 200241 9389-9397. (https://doi.org/10.1021/ bi020084j)

24 Mohan S, Nakao Y, Honda Y, Landale E, Leser U, Dony C, Lang K \& Baylink DJ. Studies on the mechanisms by which insulin-like growth factor (IGF) binding protein-4 (IGFBP-4) and IGFBP-5 modulate IGF actions in bone cells. Journal of Biological Chemistry 1995270 20424-20431. (https://doi.org/10.1074/ jbc.270.35.20424)

25 Fernandez MC, Venara M, Nowicki S, Chemes HE, Barontini M \& Pennisi PA. Igf-I regulates pheochromocytoma cell proliferation and survival in vitro and in vivo. Endocrinology 2012153 3724-3734. (https://doi.org/10.1210/en.2012-1107)

26 Milani D, Carmichael JD, Welkowitz J, Ferris S, Reitz RE, Danoff A \& Kleinberg DL. Variability and reliability of single serum IGF-I measurements: impact on determining predictability of risk ratios in disease development. Journal of Clinical Endocrinology and Metabolism 200489 2271-2274. (https://doi.org/10.1210/ jc.2003-032150)

27 Bayne ML, Applebaum J, Chicchi GG, Miller RE \& Cascieri MA. The roles of tyrosines 24,31 , and 60 in the high affinity binding of insulin-like growth factor-I to the type 1 insulin-like growth factor receptor. Journal of Biological Chemistry 1990265 15648-15652.

28 Jafari E, Gheysarzadeh A, Mahnam K, Shahmohammadi R, Ansari A, Bakhtyari H \& Mofid MR. In silico interaction of insulin-like growth factor binding protein 3 with insulin-like growth factor 1. Research in Pharmaceutical Sciences 201813 332-342. (https://doi. org/10.4103/1735-5362.235160)

29 Coutinho DC, Coletta RRD, Costa EMF, Pachi PR, Boguszewski MCS, Damiani D, Mendonca BB, Arnhold IJP \& Jorge AAL. Polymorphisms identified in the upstream core polyadenylation signal of IGF1 gene Exon 6 do not cause pre- and postnatal growth impairment. Journal of Clinical Endocrinology and Metabolism 200792 4889-4892. (https:// doi.org/10.1210/jc.2007-1661)

30 Bayne ML, Applebaum J, Underwood D, Chicchi GG, Green BG, Hayes NS \& Cascieri MA. The $\mathrm{C}$ region of human insulin-like growth factor (IGF) I is required for high affinity binding to the type 1 IGF receptor. Journal of Biological Chemistry 1989264 11004-11008.

31 van Duyvenvoorde HA, van Setten PA, Walenkamp MJE, van Doorn J, Koenig J, Gauguin L, Oostdijk W, Ruivenkamp CAL, Losekoot M, Wade JD et al. Short stature associated with a novel heterozygous mutation in the insulin-like growth factor 1 gene. Journal of Clinical Endocrinology and Metabolism 201095 E363-E367. (https://doi.org/10.1210/jc.2010-0511)

32 Fuqua JS, Derr M, Rosenfeld RG \& Hwa V. Identification of a novel heterozygous IGF1 splicing mutation in a large kindred with familial short stature. Hormone Research in Paediatrics 201278 59-66. (https:// doi.org/10.1159/000337249)

33 Batey L, Moon JE, Yu Y, Wu B, Hirschhorn JN, Shen Y \& Dauber A. A novel deletion of IGF1 in a patient with idiopathic short stature 
provides insight Into IGF1 haploinsufficiency. Journal of Clinical Endocrinology and Metabolism 201499 E153-E159. (https://doi. org/10.1210/jc.2013-3106)

34 Abuzzahab MJ, Schneider A, Goddard A, Grigorescu F, Lautier C, Keller E, Kiess W, Klammt J, Kratzsch J, Osgood D et al. IGF-I receptor mutations resulting in intrauterine and postnatal growth retardation. New England Journal of Medicine 2003349 2211-2222. (https://doi. org/10.1056/NEJMoa010107)
35 Choi JH, Kang M, Kim GH, Hong M, Jin HY, Lee BH, Park JY, Lee SM, Seo EJ \& Yoo HW. Clinical and functional characteristics of a novel heterozygous mutation of the IGF1R gene and IGF1R haploinsufficiency due to terminal 15q26.2->qter deletion in patients with intrauterine growth retardation and postnatal catch-up growth failure. Journal of Clinical Endocrinology and Metabolism 201196 E130-E134. (https://doi.org/10.1210/jc. 2010-1789)

Received 19 July 2019

Revised version received 05 September 2019

Accepted 19 September 2019 